\title{
DE FORMULA VITAE HONESTAE: uma obra de caráter político-moral
}

\author{
Leila Rodrigues Roedel*
}

SINTESE - O processo de conversão ao Cristianismo, em sua versão ortodoxa, dos povos bárbaros assentados em território do Antigo Império Romano, durante os séculos V e VII, evidencia o empenho das autoridades religiosas capazes de forjar variadas estratégias na busca do seu intento.

Nesse sentido, destaca-se a atuação de Martinho de Braga pelo seu sistemático trabalho de evangelização, do que fez parte a redação de variadas obras. Entre estas desejamos sublinhar De Formula Vitae Honestae, obra de caráter político e moral dírigida aos príncipes do referido reino, reproduzida inúmeras vezes na Idade Média a partir do século XII e inserida no conjunto de escritos conhecidos como espelho dos príncipes.
ABSTRACT - The process of the barbarian's conversion to Christianism, in its orthodox version, who settled in Ancient Roman Empire territory, during the V and VII centuries, attests the determination of the religions authorities, capable of forging various strategies, in order to achieve its purpose.

In this sense, we emphasize Martinho de Braga for his systematic work of evangelization, which was issue for many books. Among those, we would like to mention De Formula Vitae Honestae a work of political and moral character, directed to the princes of the Kingdom, which we reffered to, countless written in the Middle Ages, from the XII century on, and put in the group of writings, known as the mirror of princes.

Os povos germânicos que se estabeleceram no antigo território do Império Romano a partir do $\mathrm{V}$ século eram, em sua maioria, pagãos ou arianos. $\mathrm{O}$ longo processo de cristianização, buscando a ortodoxia, de alguns desses povos evidenciou um criativo e árduo trabalho por parte das autoridades eclesiásticas locais.

Tal processo de cristianização pode ser observado com clareza entre os suevos, grupo germano, que estabeleceu um reino no noroeste da Península Ibérica. No dito reino, há que se ressaltar o empenho do bispo Martinho, apontado de forma consensual pela Historiografia ${ }^{1}$ como um dos maiores responsáveis pela cristianização deste povo. A dedicação do referido bispo pode ser constatada não apenas em sua importante atuação na reorganização da Igreja na região, ou em seu trabaIho de fundação de mosteiros, mas também na redação da obra que desejamos no presente texto sublinhar, ou seja, De Formula Vitae Honestae. ${ }^{2}$

- Universidade Federal do Rio de Janeiro - UFRJ.

1 Ver: Martini Episcopi Bracarensis. Opera Omnia. Edit Claude W. Barlow. New Haven: Yale University Press. 1950. p. 1-10.

2 Apesar da edição já clássica de Claude W. Barlow, acima citada, optamos pela utilização de uma obra mais atualizada. MARTINHO DE BRAGA. Obras Completas. Versión castellana edición y notas 
Nesse sentido, dividimos 0 texto em quatro partes centrais destacando em cada bloco aspectos relevantes concernentes à obra mencionada.

\section{1- A inserção da obra no contexto}

Os suevos chegaram à Península Ibérica em 409 e desde então deram início à organização de um reino cuja duração se estenderia até 585 , quando foram definitivamente subordinados aos poderosos vizinhos peninsulares, os visigodos. Como povos pagãos, a princípio, hostilizaram a Igreja e dificultaram suas atividades, especialmente no que se referia ao processo de cristianização, iniciado no século I e ainda em andamento no século $\mathrm{V}$.

Apesar das dificuldades acima citadas, a tradicional organização da Igreja nas áreas urbanas permitiu que as autoridades eclesiásticas mantivessem uma relativa vitalidade até meados do século VI, quando um novo e favorável rítmo foi dado às suas atividades em decorrência de um relacionamento mais íntimo entre esta instituição e a monarquia sueva. Nesta ocasião, segundo as principais fontes para o estudo dos suevos na região, ${ }^{3}$ o rei influenciado pela cura milagrosa do seu filho teria se convertido ao Catolicismo.

É evidente que tal processo não pode ser observado segundo uma ótica tão simplista, já que evidentemente as vantagens políticas de uma conversão puderam claramente ser percebidas pela nobreza sueva. Entre outros aspectos poderíamos, por exemplo, mencionar o fato de que a elite autóctone era em sua maioria católica e que a unidade política e a total integração das populações do reino, pretendidas pelas autoridades suevas, não se fariam sem um elemento sólido capaz de promover a identidade plena entre essa população e os invasores, bem como possibilitar a total integração do reino. De qualquer forma não nos cabe aqui a análise mais detalhada do motor dessa conversão, ${ }^{4}$ antes sim, como o subtítulo indica, destacar a inserção da obra De Formula Vitae Honestae neste contexto de conversão e cristianização.

A conversão propiciou um ambiente favorável à redação de obras cuja função de uma maneira ou de outra associava-se à cristianização, na medida em que divulgavam valores cristãos ou incorporados pelo Cristianismo e criticava crenças e práticas pagãs. Evidentemente tal conclusão pauta-se, sobretudo, na quantidade de escritos organizados entre os anos 559 e 580, após um perído de quase um sé-

por Ursicino Dominguez del Val. Madrid: Fundación Universitária Española, 1990. p. 157-163.

3 ISIDORO. Las Historias de los Godos, Vândalos y Suevos. Estudio, edición crítica y traducción Cristobal Rodrigues Alonso. León: La Caja de Ahorros y Monte de Piedad de Leon y El Archivo Historico Diocesano de León, 1975. p. 319 e GREGOIRE DE TOURS. De Miraculis S. Martini Turonensis, L. I, cap. XI apud COSTA, Avelino de Jesus. S. Martinho de Dume. XIV Centenánio de sua Chegada à Península. Bracara Augusta, Braga, v. 2. p. 288-325, 1950. p. 290.

4 Ver: CHAVES, Luis. S. Martinho de Dume e a Sociedade Suévica. Bracara Augusta, Braga, v. 11/12, p. 113-120, 1967/1968. GIGANTE, José Antonio Martins. "Ambiente e Significado da Legislação Particular do Concilio de Braga". In: Actas da XIV Semana Internacional de Direito Canônico O Concilio de Braga e a Funçăo da Legislaçäo Particular da Igreja. Braga. p. 13-31, 1975; OLIVEIRA, Miguel de. "S. Martinho de Dume e a Conversão dos Suevos". In Lumen, Lisboa, v. 14, p. 636-647, 1950, entre outros. 
culo ${ }^{5}$ sem que encontrássemos na região uma produção semelhante. De qualquer forma, ainda que de modo geral as autoridades religiosas tenham aproveitado tal momento para reorganizar e fortalecer a Igreja, no que concerne à redação de obras cristianizadoras, tal tarefa foi assumida apenas por um bispo, Martinho de Braga, como veremos adiante.

Dessa forma, há que se compreender a obra em questão, em seu sentido mais geral, como um dos elementos do amplo processo de cristianização sob o qual vivia a Galiza. Ou melhor, como um dos muitos mecanismos desenvolvidos pelas autoridades religiosas com esse fim.

\section{2 - Identificação do autor e da obra}

\section{$O$ autor}

Martinho nasceu em torno de 520, na Panônia, antiga província oriental romana. Ainda que as informações sobre suas origens familiares sejam repletas de lacunas, seu nome e sua formação cultural, verificada em sua produção literária, indicam sua possivel ascendência romana.

Tendo chegado à Galiza, núcleo do reino suevo, por volta de 559, Martinho, ao que tudo indica, ${ }^{6}$ teria anteriormente vivido no reino franco, de onde partira com uma missão diplomática. Mas, esta não é a única hipótese existente para justificar a sua presença no reino suevo. As explicações sobre as razões que o teriam levado ao noroeste peninsular são muitas e, se em alguns casos podem ser conciliadas, em outros são excludentes.

Segundo Gregorio de Tours, ${ }^{7}$ Martinho teria se dirigido à Península com o intuito deliberado de promover a cristianização da população sueva, cuja opção religiosa, distante da ortodoxia, era do conhecimento de todos. Assim, Martinho atuara na cura milagrosa do príncipe suevo, na tentativa de convencer o monarca e toda a sua corte sobre a necessidade de converterem-se à verdadeira fé.

Se no relato acima lenda e História se misturam, nem sempre a Historiografia buscou explicar a presença de Martinho, em terras tão distantes do seu local de nascimento, a partir de estímulos não materiais. Dessa forma, há quem acredite na possibilidade de que Martinho estivesse inserido no projeto de reconquista, empreendido por Justiniano. ${ }^{8}$ Ou seja, desejando reconstituir a antiga unidade do Império Romano, o imperador teria enviado o religioso para o estabelecimento de maiores vínculos com a região, numa espécie de preparativo para a sua chegada triunfante.

5 O fim da Crônica de Hidácio, bispo de Chaves, contemporâneo das invasōes, em 467, inaugura um periodo de obscuridade sobre o reino suevo. Não há fontes escritos na região ou sobre ela, até 559 , quando Martinho chega à Galiza.

6 Martinho não só viveu, como fez amigos entre os francos, ver MORALEJO LASO. "Sobre el Sentido de Unos Versos de Venâncio Fortunato a San Martin Dumiense en Relación con la Tradición Jacobea". Compostellanum. Santiago de Compostela, n. 3, trim. p. 340-344, 1958. COSTA, Avelino. op. cit., p. 292.

8 AMARAL, João Ferreira. "O Periodo de S. Martinho: O Reino Suevo (550-585): "Alguns Condicionalismos Sócio-Econômicos". Bracara Augusta, Braga, v. 36, p. 269-284, 1982. p. 282. 
Assim, como podemos observar, as razões que teriam levado Martinho à Galiza estão longe de serem determinadas. $O$ mesmo não pode ser dito sobre o elemento que estimulou toda a sua atuação junto aos suevos. Aqui claramente podemos identificcar o seu ímpeto cristianizador.

Ao chegar ao reino suevo, Martinho deparou-se com uma Igreja inoperante e desorganizada, conseqüência de vários anos sob a pressão das autoridades políticas da região que eram suevos arianos. $O$ fato de sua chegada coincidir com o início de uma aproximação entre a Monarquia e a Igreja pode indicar uma realidade, fruto exclusivamente do seu empenho pessoal ou, o mais provável, o estabelecimento de uma nova política religiosa por parte dos reis suevos como desdobramento de uma aliança com os francos católicos.

Tal possibilidade, entretanto, não deve ofuscar de todo o papel de Martinho nesse processo, não apenas porque certamente estivera presente nas negociações entre os dois povos, caso elas tenham ocorrido, mas principalmente pelo trabalho que desenvolveu no sentido de reorganizar e fortalecer a Igreja, do que fizera parte a sua atuação cristianizadora.

Entretanto, não apenas o seu trabalho de articulador religioso deve ser destacado, igualmente merece atenção o trabalho do político que foi capaz de promover entre a Igreja e a Monarquia um nivel de relacionamento que tornou viável a identidade de interesses, sobretudo no que se referia à unidade política e religiosa do reino. Assim, se o início de uma aliança entre a Igreja e a Monarquia não pode ser indubitavelmente atribuído à atuação pessoal de Martinho, a certeza de que esse grau de entrosamento decorre da sua ação é algo indiscutível.

Logo, o empenho de Martinho resultou nos anos posteriores a 550, entre outras coisas, na oficialização da conversão do monarca e sua corte, na construção de mosteiros, na criação de escolas, na reforma litúrgica e disciplinar no seio da Igreja e na redação de obras ascético-morais e canônico-litúrgicas.

A formação cultural de Martinho dentro da tradição clássica, ${ }^{9}$ seu empenho na cristianização e seu alto posto na hierarquia eclesiástica - acumulou por mais de dez anos duas sedes episcopais, sendo uma delas a metrópole bracarense - revelaram o escritor.

Martinho escreveu, pelo menos, uma dezena de obras que poderíamos dividir em dois grupos: ascético-morais e canônico-litúrgicas. ${ }^{10}$ De Formula Vitae Honestae, inserida no primeiro grupo, caracteriza-se, sobretudo no que concerne ao seu autor, pela possibilidade de revelar não apenas o homem religioso, mas também o homem político que mencionamos há pouco.

\section{A obra}

De Formula Vitae Honestae foi escrita entre 570 e 580, período compreendido entre o começo do governo do rei Miro e a morte de Martinho de Braga. Sua redação é clara quanto ao dado que objetivamente levou o autor a escrevê-la, ou seja, os insistentes pedidos do monarca, Miro. Vejamos:

9 Ver: FONTÁN, Antonio. "Martín de Braga, un Testigo de la Tradición Clasica y Cristiana". Anuario de Estudios Medievales, Barcelona, v. 9, p. 331-341, 1974-1979.

10

Ver Martín de Braga. op. cit. 
"No ignoro, rey clementisimo que la ardentísima sed de tu espíritu procura permanecer insaciablemente en las copas de la sabiduria, y que andas ansiosamente en busca de las fuentes de donde manan la aguas de la ciencia moral. Y por eso, muchas veces estimulas a mi pequeez con tus cartas a que escribiendo con frecuencia alguna carta a tu alteza, te dirija algunas palabras bien sean de consuelo o de exhortación".11

As linhas acima indicam ainda, assim como outros trechos da obra, que entre o governante e o escritor existiam mais do que simples vínculos formais entre o bispo, representante da Igreja galaica e o monarca do reino. Ou seja, as palavras de Martinho apontam para uma relação que teria possivelmente feito deste religioso um dos conselheiros particulares do rei suevo. Tal iniciativa, aliás, demonstrar-se-á nos séculos seguintes bastante comum entre outras monarquias germanas, ou seja, a presença nas cortes de religiosos orientando os monarcas. Só na própria Península Ibérica poderíamos, por exemplo, lembrar o caso de Leandro junto ao rei Recaredo, ou um pouco mais tarde, de Isidoro junto a Sisebuto.

Se a proximidade entre Miro e Martinho permitiu ao primeiro usufruir de conselhos de um homem culto, ao segundo não foi menos vantajosa tal aproximação. Entre outras coisas, Martinho, além, evidentemente, de poder contar com o apoio político para organizar internamente a Igreja de forma a fortalecê-la, pôde dedicar um trabalho de forte cunho moral e, portanto, próximo da mensagem cristã, não apenas ao monarca mas, como veremos, a toda a corte.

Assim, não há dúvidas de que De Formula Vitae Honestae estivera inserida no processo de cristianizaçáo da Galiza, especialmente revigorado a partir de uma maior aproximação entre as autoridades eclesiásticas e politicas da região. Havendo ainda a esse respeito que destacar que fora concebida exclusivamente para um determinado segmento da sociedade, como poderemos observar neste pequeno trecho:

"No he escrito este libro de modo particular para tu instrucción, siendo natural en ti la sagacidad de la sabiduria, sino que lo escribi de un modo general para aquellos que ayudan en tu ministerio y que está bien que lo lean, entiendan y retengan". ${ }^{2}$

Objetivando, portanto, atingir a elite política do reino e atender aos desejos do monarca por uma obra que tratasse da Ciência Moral, Martinho buscou uma mensagem simples, pouco rebuscada. Segundo ele mesmo

"se refiere únicamente a aquellas cosas, que sin tener un precepto de las divinas Escrituras, únicamente por la ley natural de la razón humana pueden cumplirlas incluso los laicos que viven recta y honestamente. ${ }^{13}$

De Formula Vitae Honestae está dividida em oito capítulos. Quatro estão dedicados a cada uma das virtudes: la prudencia, la magnanimidad, la continencia e la justicia. A estes capítulos correspondem outros quatro, cujo maior objetivo, segundo o próprio texto, é a lembrança de que o equilíbrio no cumprimento das orienta-

11 A partir daqui passo a referir-me à obra De Formula Vitae Honestae pelas suas iniciais (DFVH) e sempre me remetendo à edição realizada por Ursicino Dominguez del Val, já citada. DFVH, introduçăo.

12 Idem.

13 Idem. 
ções deveria ser mantido, são estes: Medida y régimen de la prudencia; Régimen de la fortaleza; Límite de la templanza e Cómo se ha de dirigir la justicia.

A redação sentenciosa e, muitas vezes, sem encadeamento ${ }^{14}$ não esconde, contudo, a existência de um fio condutor, ou seja, o desejo de fornecer aos homens da corte que governam um modelo de conduta. Dessa forma, De Formula Vitae Honestae enquadra-se entre aquelas obras claramente identificadas com os espelhos dos principes. ${ }^{15}$

Estes escritos que buscavam sublinhar as qualidades dos governantes e/ou apresentar normas de comportamento para a maior depuração desses adjetivos eram conhecidos desda a antigüidade grega. Todavia, é nesse momento, a partir de meados do século VI, na Galiza, que passam a ser particularmente associados ao Criștianismo. A proliferação dessas obras desde então vincular-se-á, especialmente, ao trabalho de justificação do poder monárquico, no qual o clero empenharse-á.

\section{3 - A herança senequista na obra}

Dentro de uma linha didática o autor justifica o título da obra retomando o antigo tema das quatro virtudes essenciais ao homem, presente numa literatura filosófica, anterior ao Cristianismo e, como já mencionamos, originariamente tratada pela filosofia greco oriental.

"Según el parecer de muchos sabios, a cuatro se reducen las clases de virtudes mediante las
cuales el espiritu humano puede llegar a una vida virtuosa. La primera de ellas es la pruden-
cia, la segunda la magnanimidad, la tercera la templanza y la cuarta la justicia. Cada una de
ellas, mediante la práctica de las obras, se esplican más abajo, hacen a un hombre virtuo-
so". ${ }^{16}$

A proximidade cronológica, porém, indicou-lhe um viés cristianizado ao abordar a temática, de forma que De Formula Vitae Honestae foi facilmente associado ao estóico Sêneca. Tal associação, inclusive, permitiu à referida obra sua reprodução em pelo menos 635 manuscritos por toda a Idade Média, ${ }^{17}$ sendo a maior parte destes do periodo compreendido entre os séculos XII e XV. Țal reprodução ocorreu, entretanto, em geral, pelo nome que Isidoro de Sevilha, certamente por não tê-la conhecido integralmente, conferiu-lhe: De diferentiis quattuor uirtutum.

Dessa forma, segundo o especialista Ursicino Dominguez del Val, ${ }^{18}$ De Formula Vitae Honestae, ao que tudo indica desprovida de sua introdução, que como vimos, definia seu público alvo com muita clareza, teve sua autoria atribuida a Sêneca. Curiosamente nenhuma das obras autênticas deste estóico foi representada por tantos exemplares medievais. ${ }^{19}$

14 MARTINS, Mario. Correntes da Filosofia Religiosa em Braga (Séculos IV-VII). Porto: Tavares Martins, 1950. p. 233.

15 TOUCHARD, Jean (dir). Histónia das Idéias Politicas. Lisboa: Europa-América, 1959. p. 64-65; MIETHKE, Jurgen. Las Ideas Politicas en la Edad Media. Buenos Aires: Biblos, 1993. p. 19-27.

16

17 FONTÁN, Antonio. "Martín de Braga. Proyección Histórica de su persona y su obra". In: Humanismo Romano. Barcelona: Planeta, 1974. p. 202.

18

19

FONTÁN, Antonio. op. cit., p. 202. 
Principalmente devido às cartas apócrifas que circulavam na Idade Média, indicando que o filósofo cordovês mantivera correspondência com São Paulo, bem como devido ao fato de ter sido morto por um imperador romano, Sêneca possuía, não apenas status de cristão, mas também de mártir. Tal fato contribuiu consideralvemente para a popularidade do escrito martiniano, que inegavelmente se identificava com o estilo de Sêneca.

É provável que Martinho tivesse conhecido De Officis, uma das obras perdidas do filósofo estóico, e se baseado nela para desenvolver sua mensagem, evidentemente adequando-a, e certamente não copiando, como defendeu na década de cinqüenta o professor Severiano Tavares, ${ }^{20}$ nos pontos que desejava abordar.

Martinho de Braga, guiando-se, por um lado, pelos apelos do rei e, por outro, pelo seu desejo de, ainda que dissimuladamente, divulgar valores incorporados da moral pagã pelo Cristianismo junto a um grupo político importante dentro do reino, desenvolveu esta obra no âmbito da Filosofia Moral, destacando assim as virtudes da prudênicia, da magnanimidade, da moderação e da justiça.

\section{4- O caráter político e moral no tratamento das virtudes}

A busca da razão natural é algo enfatizado em toda a obra. Entretanto, ainda que sem mencionar o Cristianismo ou as Sagradas Escrituras, Martinho de Braga, pouco a pouco, nela introduz elementos claramente cristãos.

Se a doutrina moral martiniana faz-se inegavelmente presente, também os elementos de sua proposta política lá estão, visto que De Formula Vitae Honestae fora escrita para governantes. Assim, conselhos são dados não apenas para o homem, mas igualmente para o político de quem se espera muito mais do que bom senso, entre outras coisas, um comportamento prudente, magnânimo, moderado e justo.

\section{A prudência}

Baseado no acima exposto, o modelo do prudente é construído a partir da negação de uma conduta que privilegiasse o fugaz:

"No profeses admiración a las cosas transitorias". ${ }^{21}$

Tal comportamento deveria, porém, ter uma justa medida, sob o risco de tornar-se intransigente e imutável:

"Y según las exigencias de los tiempos y diversidad de asuntos lo requiera, acomódate a las circunstancias [...]". 22

O prudente deveria ainda ser sábio o bastante para reconhecer no passado as lições do futuro:

"[...] quien no medita acerca del pasado, pierde la vida, y el que no reflexiona de antemano sobre el futuro incautamente tropieza en todo. ${ }^{23}$

20 TAVARES, Severiano. "O Senequismo de S. Martinho de Dume". Revista Portuguesa de Filosofia. Lisboa, v. VI, p. 381-387, 1950.

21 DFVH, cap. I.

22 Idem.

23 Idem. 
Nada mais desagradável ao governante do que a surpresa diante do inevitável. A valorização do passado compreende-se, portanto, particularmente por representar uma fonte que o prudente poderia consultar e apreender. Seria pouco provável que o governante viesse a se deparar, no seu dia-a-dia, com uma situação totalmente nova caso se interessasse pelo passado. Em outras palavras, este conhecimento o capacitaria melhor na medida em que lhe permitiria a construção de referenciais variados sobre diversos assuntos. Em suma, a surpresa poderia ser evitada. Assim, insiste o autor:

"Porque quien es prudente no dice: No pensé que esto pudiera acontecer ${ }^{24}$

A objetividade era também um fim a ser alcançado. O governante não deveria desperdiçar seu tempo. Logo, se o conhecimento do passado era proveitoso a ponto de que devesse o monarca dedicar-lhe atenção, este não deveria, porém; perderse em construções de projetos irrealizáveis. Assim, uma avaliação para o discernimento entre o que poderia e o que não poderia ser feito deveria, invariavelmente, ocorrer sempre que a possibilidade de novos empreendimentos se fizesse presente. Vejamos o próprio texto:

"No des cabida a pensamientos inútiles y vanos y semejantes a un sueo, en los cuales si tu alma se entretiene, quedará sumida en tristeza cuando arregles todon. ${ }^{25}$

A adulação, em geral tão próxima dos governantes, deveria ser afastada, assim como a frivolidade e a impulsividade. Haveria, entretanto, que se buscar o equilíbrio, evitando-se os exageros, tão danosos ao governante, quanto as carências, pois o excesso de prudência poderia, por exemplo, revelar o político inseguro e violento.

"[...] si la prudencia excede sus límites, penetrarás en el terreno de la astucia y de la timidez, serás tachado de investigador de secretos y de escrudiñador de toda clase de culpas, serás tildado de cobarde, reciloso [...]". ${ }^{26}$

\section{A magnanimidade}

Das virtudes tratadas é a que reune menos considerações do autor. Identificando magnanimidade com fortaleza, enquanto qualidade daquele que é forte e virtuoso, as palavras aqui aplicadas complementam as proposições anteriores que destacavam a necessidade de uma conduta equilibrada. Deveria, pois, o soberano evitar os excessos, as vinganças, as mesquinharias, atitudes estas que o tornariam indigno. Assim expressa-se Martinho:

"Ten entendido que el perdonar es un honroso y excelente modo de vengarse" ${ }^{27}$

Ser magnânimo implicava também em não se expor diante dos perigos, assim como, evidentemente, não colocar em risco a segurança e a paz interna do reino, na medida do possivel. Ou seja, sem que tal atitude resultasse em covardia.

\footnotetext{
24 Idem. 
"Serás magnánimo, si no buscas temerario los peligros, ni timido les tienes horror [...] la medida de la magnanimidad consiste en no ser ni timido ni audaz". ${ }^{28}$

A situação do reino poderia explicar melhor as palavras acima; vejamos: do ponto de vista externo, havia um ambiente marcado especialmente pela pressão constante dos visigodos, a possibilidade do desencadeamento de uma guerra deveria ser, pois, evitada, ou melhor, não poderia se dar a partir de uma atitude precipitada do governante. A superioridade militar e numérica do inimigo em potencial era reconhecida, assim como os possiveis desdobramentos de um enfrentamento. Todavia, a postura do governante não poderia indicar fraqueza, antes sim, segundo as orientações da obra analisada, a serenidade própria daquele que é cauteloso sem ser medroso.

No que concerne ao interior do reino não se pode pretender a existência de uma total harmonia, entretanto, as principais dificuldades referentes ao convivio entre a população autóctone e os suevos já havia sido superada, ao menos em seus pontos mais críticos. Um aspecto talvez ainda a dividir a população referir-se-ia à heterogeneidade religiosa existente no seio do reino.

Contudo, apesar de que houvesse uma política de integração sendo construida, nesse momento, em torno do Cristianismo, não deveria o monarca, por exemplo, tentar a imposição do Catolicismo a uma população cujas práticas e crenças pagãs faziam parte do seu passado representando, inclusive, sua própria identidade cultural. Caberia, sim, ao monarca não vacilar diante de todas as oportunidades de empreender uma política de unidade, sem com isso provocar, no entanto, fortes descontentamentos.

\section{A continência}

De todas as virtudes é sobre esta que o autor se detém por mais tempo. Seu enfoque se faz a partir de duas óticas, a pessoal e a social. São alternados, portanto, os conselhos dados ao homem de origem "bárbara" com os fornecidos ao governante.

Apesar do fato de que a maioria das questões tratadas nesse item venham incidir, aparentemente, sobre o homem e não o político, precisamos destacar que a idéia de uma conduta pessoal compatível com o governante perpassa toda a abordagem.

Assim, enquanto o homem é aconselhado sobre a necessidade de evitar a concupiscência e a gula, sob a alegação de que tais práticas o tornariam menos digno, o governante é orientado sobre a importância de rechaçar as adulações.

O tema das adulações, aliás, já fora enfocado mais de uma vez, o que torna esse aspecto, no mínimo, foco de curiosidade. Ao que tudo indica, poderíamos deduzir que Martinho em contato freqüente com a corte estaria nos fornecendo indicativos de que a prática da adulação era ali uma constante. De outra forma não haveria como justificar tanto interesse pelo assunto. 
A mensagem, entretanto, que mais atenção chama sobre as concepções políticas presentes no texto refere-se, não aos possiveis aduladores da corte, mas às populações simples; vejamos:

"Todos deben ser para ti iguales, no desprecies enorgullecido a los inferiores". ${ }^{29}$

O momento acima é, possivelmente, um dos melhores exemplos contidos na obra no qual mais claramente se evidencia o objetivo do autor, enquanto orientador do monarca e demais governantes num assunto predominantemente político.

$\mathrm{Na}$ verdade, sabemos que sendo o autor um bispo comprometido com o processo de cristianização, ainda que a proposta da obra não fosse o ensino de, segundo palavras do escritor, "cosas arduas y perfectas, que son para pocos y que las pratican los afamados santos", ${ }^{30}$ seria natural, como já reconhecemos anteriormente, que os princípios cristãos, ou os valores do humanismo pagão incorporados pelo Cristianismo, conduzissem a obra com a primazia, portanto, de uma mensagem de cunho moral. Aqui, porém, a mensagem é, sobretudo, política. A idéia de que todos os homens devessem ser compreendidos como iguais sem que os "inferiores" fossem desprezados, demonstra o reconhecimento de uma hierarquia política, onde os conceitos de inferiores e superiores, não pertinentes numa mensagem exclusivamente de moral cristã, são utilizados.

Dando continuidade a essa linha, logo adiante expressa-se 0 autor:

"Viviendo con rectitud, no tengas miedo a los superiores". ${ }^{31}$

No texto, desde então, cresce em ênfase o caráter político da obra martiniana, com destaque para aquelas questões que são próprias dos governantes; vejamos mais um exemplo, cuja menção não pode ser dispensada devido à sua importância para a ilustração de nossas consideraçōes:

"El sabio no pertubará las costumbres públicas, ni atraerá sobre si las miradas del pueblo con novedades de vida. Tras esto viene la virtud de la justicia". ${ }^{32}$

De Formula Vitae Honestae não apenas evidencia, nas palavras acima transcritas, a força que o direito consuetudinário tem entre aquela população, como fornece também a medida de uma possivel interferência real. Certamente, a dominação de uma minoria sueva sobre uma população romanizada implicou no aparecimento de inúmeras diferenças que, se em alguns casos passaram despercebidas, em outros precisaram ser ajustadas. $O$ texto não nega a necessidade dos ajustes, mas indica a fórmula remetendo-se à última das virtudes abordadas, a justiça.

\section{A justiça}

Mas, o que é a justiça para o autor? Aqui o escritor cristão comedido revela-se por inteiro. Sem desvios ou artimanhas remete-se diretamente a Deus, dando um novo tom à sua obra.

\footnotetext{
29 DFVH, cap. III.

30 DFVH, introduçäo.

31 DFVH, cap. III.

32 Idem.
} 
"Justicia no es constitución nuestra sino ley divina. [...] Todos aquellos, por conseguiente que deseáis praticarla, ante todo temed a Dios y amadlo, para que seáis amados por Dios". ${ }^{33}$

A preocupação evidenciada em apresentar, muitas vezes num texto sem encadeamento, conselhos pautados apenas na razão natural extingue-se, ou melhor, a razão natural passa a ser identificada com Deus.

Um comportamento ideal resultaria, portanto, numa conduta que buscasse, na medida do possivel para um leigo, imitá-10. Proposta naturalmente identificada com o modelo de vida virtuosa indicada na obra em questão, De Formula Vitae Honestae.

Esse modelo, porém, apresentava-se, algumas vezes, como algo aparentemente contraditório. Assim, por exemplo, se por um lado a imitação de Deus implicava em defender a verdade, por outro lado existiam circunstâncias em que a mentira deveria ser aplicada; vejamos:

"Y si en alguna ocasión te ves obligado a emplear la mentira, hazlo siempre, no en favor de la falsedad, sino de la verdad; y si acontece que has de salvar la lealtad por medio de la mentira, no mientas, sino más bien excúsate; porque tratándose de una causa honesta [...] [. ${ }^{34}$

Logo, os fins justificavam os meios. Um bom governante deveria, portanto, ter a capacidade de avaliar a necessidade da mentira e utilizá-la, não como prática continua, mas em prol de uma causa maior.

Ser justo implicava, ainda, na capacidade de ser honesto e não omisso. Ou seja, aos governantes atribuia-se a obrigação de não causar danos a ninguém, mas, sobretudo, a estes caberiam ações contundentes contra aqueles que cometessem as infrações.

"Para ser justo no sólo no harás dao, sino que estorbarás que lo hagan; porque el no hacer daño no es justicia, sino desinterés por lo ajeno"..$^{35}$

À justiça foi dado o status de virtude imprescindivel aos bons governantes, condição também para o reconhecimento de todos, encaminhamento, portanto, adequado, a um monarca que desejasse ser legitimado.

"Serás amable a Dios si lo imitas en querer favorecer a todos y no perjudicar a ninguno. Entonces todos te llamarán varón justo, te seguirán, venerarán y amarán". ${ }^{36}$

$\mathrm{Na}$ busca de um perfil justo, não caberia o privilégio de uns em detrimento de outros. Todos deveriam ser tratados em condições de igualdade, na medida em que os governantes deveriam atuar para o benefício, não apenas de um grupo restrito de suevos, mas de toda a população do reino, sob pena de comprometer um objetivo político maior, ou seja, a construção da integração do reino.

Nas entrelinhas, no "não dito". ou no sugerido, já há, contudo, a clareza que a mensagem da obra De Formula Vitae Honestae relaciona-se com uma concepção de integração política do reino suevo construida dentro de um projeto maior. Isto é, uma integração inserida num plano divino que compreenderia a necessidade de

33 DFVH, cap. IV:

34 Idem.

Idem. 
homens no governo orientados em sua conduta moral e política a partir dos príncipios expostos na obra martiniana.

\section{Considerações finais}

Ainda que Martinho de Braga só evidencie, em palavras, as referências que faz ao Cristianismo ao tratar da virtude da justiça, todo o seu raciocínio, nesta obra dedicada ao monarca e seus auxiliares no governo, pauta-se na razão natural enquanto princípio identificado com as leis divinas.

Dessa forma, ao longo da De Formula Vitae Honestae claramente estão associados, repito, mesmo que de maneira dissimulada, dois elementos distintos que, segundo a proposta da obra, complementam-se, ou seja, as leis de Deus e um modelo legitimo de governante.

Assim, em mensagem implícita na obra, a construção da legitimidade política dos governantes fora apresentada numa relação de subordinação a um plano sagrado. Tal legitimidade só haveria de ser plenamente alcançada a partir de uma conduta baseada nos valores, princípios e propostas fornecidos por Deus, revelados a partir da interpretação feita pelos eclesiásticos das Sagradas Escrituras.

$O$ reconhecimento, ainda que provavelmente inconsciente, da autoridade eclesiástica para a interpretação acima mencionada, certamente influenciou o rei Miro, quando dos seus apelos ao bispo bracarense no sentido de que escrevesse uma obra cujo tom fosse exortativo e conselheiro. Em outras palavras, a aceitação de que aos religiosos cabia o papel de intermediários entre Deus e os homens pode ter servido de estímulo para a redação da obra. É possivel, portanto, que pairasse no ar mais do que desejos por conselhos; na verdade, parecia existir também uma grande dúvida: enfim, qual deveria ser a função de um rei cristão?

A resposta à pergunta não formulada claramente fora respondida, ainda que também de forma implícita, na obra analisada. Em suma, a leitura da De Formula Vitae Honestae sugere que caberia ao monarca, assim como aos seus auxiliares no governo, garantir a aplicação e a manutenção das leis divinas. Para tal, fazia-se imprescindível uma vida pautada no conjunto de valores pregados pelo Cristianismo, evidenciado na obra em questão.

\section{Bibliografia}

\section{Fontes Primárias}

GREGOIRE DE TOURS. De Miraculis S. Martini Turonensis, L. I, cap. XI apud COSTA, Avelino de Jesus. S. Martinho de Dume. XIV Centenário de sua Chegada à Peninsula. Bracara Augusta, Braga, v. 2. p. 288-325, 1950.

ISIDORO. Las Historias de los Godos, Vândalos y Suevos. Edición critica y traducción Cristobal Rodrigues Alonso. Leon: La Caja de Ahorros y Monte de Piedad de Leon y El Archivo Historico Diocesano de León, 1975.

MARTINHO DE BRAGA. Obras Completas. Versión castellana edición y notas por Ursicino Dominguez del Val. Madrid: Fundación Universitária Española, 1990.

MARTINI EPISCOPI BRACARENSIS. Opera Omnia. Edit Claude W. Barlow. New Haven: Yale University Press. 1950. 


\section{Fontes Secundárias}

AMARAL, João Ferreira. O Periodo de S. Martínho: O Reino Suevo(550-585):Alguns Condicionalismos Socio-Econômicos. Bracara Augusta, Braga, v. 36, p. 269-284, 1982.

COSTA, Avelino de Jesus. S. Martinho de Dume. XIV Centenário de sua Chegada à Península. Bracara Augusta, Braga, v. 2. p. 288-325, 1950.

CHAVES, Luis. S. Martinho de Dume e a Sociedade Suévica. Bracara Augusta, Braga, v. 11/12, p. 113$120,1967 / 1968$.

FONTÁN, Antonio. Martín de Braga, un Testigo de la Tradición Clasica y Cristiana. Anuario de Estudios Medievales, Barcelona, v. 9. p. 331-341, 1974-1979.

. "Martín de Braga. Proyección Histórica de su persona y su obra". In: Humanismo Romano. Barcelona: Planeta, 1974.

GIGANTE, José Antonio Martins. "Ambiente e significado da legislação particular do Concilio de Braga". In: Actas da XIV Semana Internacional de Direito Canônico O Concilio de Braga e a Funçäo da Legislação Particular da Igreja. Braga. p. 13-31, 1975.

MADOZ, José. Citas y Reminiscencias clásicas en los Padres españoles. Sacris Eruditi, Bruge, n. 5, 1953.

MARTINS, Mario. Correntes da Filosofia Religiosa em Braga (Séculos IV-VII). Porto: Tavares Martins, 1950.

- A Formula Vitae Honestae em Jean Courtecuisse e Cristiana de Pisano. Revista Portuguesa de Filosofia. Braga, v. 12, p. 125-137, 1951.

MIETHKE, Jurgen. Las Ideas Politicas en la Edad Media. Buenos Aires: Biblos, 1993.

MORALEJO LASO. Sobre el Sentido de Unos Versos de Venâncio Fortunato a San Martin Dumiense en Relación con la Tradición Jacobea. Compostellanum. Santiago de Compostela, n. 3, trim. p. 340-344, 1958.

OLIVEIRA, "Miguel de. S. Martinho de Dume e a Conversão dos Suevos". Lumen, Lisboa, v. 14, p. 636$647,1950$.

TAVARES, Severiano. "O Senequismo de S. Martinho de Dume". Revista Portuguesa de Filosofia. Lisboa, v. VI, p. 381-387, 1950.

TOUCHARD, Jean (dir). História das Idéias Políticas. Lisboa: Europa-América, 1959. p. 64-65. 